\title{
U.S. Economic Growth, Relatively Speaking
}

$\mathrm{P}$ ublic discussion of many issues - current account deficits, federal budget deficits, Social Security reform, high oil prices, a possible housing price bubble, and Chinese exchange rate policy, to name a few of the more prominent ones-has obscured the point that, relatively speaking, the U.S. economy has expanded at a healthy pace. The table illustrates this point by juxtaposing the performance of the U.S. economy with that of other high-income countries.

In the table, the values on the left-hand side of the columns show GDP growth for the G-7 countries for 1995-2002, 2003, and 2004, as well as the International Monetary Fund's projections for 2005. ${ }^{1}$ Over the past ten years, U.S. economic growth has compared favorably with that of the other G-7 countries. Using the simple average of annual growth rates for 1995-2002, one sees that the English-speaking G-7 members converge at the top. The United States, with a growth rate of 3.2 percent, trails only Canada, which grew at a rate of 3.5 percent. More recently, U.S. economic growth has exceeded the growth of the other six countries. For 2003, the U.S. economy grew at a 3 percent rate. The United Kingdom and Canada grew at a pace roughly 1 percentage point slower, and Japan grew at a pace roughly half the U.S. rate. Meanwhile, the three continental European countries generated negligible growth. G-7 growth accelerated in 2004. The U.S. economy grew at a 4.4 percent rate, more than 1 percentage point faster than the growth in the second-fastest country, the United Kingdom. Despite their accelerating growth, the three continental European countries continued to grow relatively slowly.

Projections for 2005 suggest that the United States is likely to continue to lead G-7 countries in economic growth. Despite some slowing, U.S. economic growth is projected to be 3.6 percent, which is 0.8 percentage points greater than the projection for the next-best performer, Canada.

Productivity growth is the key reason for the relatively strong U.S. performance. In the table, the values on the right-hand side of the columns (in bold) show G-7 productivity growth for 1995-2002, 2003, and
2004. Productivity, as measured by output per worker for the entire economy, has increased at a faster rate in the United States than in any other G-7 country over the past ten years. For the period 1995-2002, U.S. productivity increased at an average annual rate of 1.9 percent. The second leading country in terms of productivity growth was Canada, with an increase of 1.5 percent. For 2003, U.S. productivity growth was 2.1 percent. The United Kingdom, with a rate of 1.8 percent, was second. A similar ranking holds for 2004, with U.S. growth at 3.3 percent and British growth at 2.5 percent.

Regardless of how one assesses the economic challenges facing the U.S. economy, U.S. growth has been noteworthy. Moreover, such growth generates resources to confront these challenges.

-Cletus C. Coughlin

\begin{abstract}
${ }^{1}$ A graphical representation of these data, as well as the productivity data used later, can be found in International Economic Trends Supplement. In the February 2005 issue, see pp. 2-3 for the economic growth data and pp. 12-13 for the productivity data.
\end{abstract}

\section{G-7 Output and Productivity (annual percent change)}

\begin{tabular}{lcccc} 
& \multicolumn{4}{c}{ Output growth / Output per worker* } \\
\cline { 2 - 5 } & $\mathbf{1 9 9 5 - 2 0 0 2}$ & $\mathbf{2 0 0 3}$ & $\mathbf{2 0 0 4}$ & $\mathbf{2 0 0 5}$ (projected) \\
\hline United States & $3.2 / \mathbf{1 . 9}$ & $3.0 / \mathbf{2 . 1}$ & $4.4 / \mathbf{3 . 3}$ & 3.6 \\
Canada & $3.5 / \mathbf{1 . 5}$ & $2.0 / \mathbf{- 0 . 3}$ & $2.0 / \mathbf{1 . 1}$ & 2.8 \\
France & $2.4 / \mathbf{0 . 5}$ & $0.9 / \mathbf{1 . 4}$ & $2.1 / \mathbf{2 . 0}$ & 2.0 \\
Germany & $1.5 / \mathbf{1 . 0}$ & $-0.1 / \mathbf{0 . 8}$ & $1.0 / \mathbf{0 . 7}$ & 0.8 \\
Italy & $1.8 / \mathbf{1 . 0}$ & $0.4 / \mathbf{0 . 0}$ & $1.1 / \mathbf{0 . 3}$ & 1.2 \\
Japan & $1.1 / \mathbf{1 . 3}$ & $1.4 / \mathbf{1 . 6}$ & $2.6 / \mathbf{2 . 4}$ & 0.8 \\
United Kingdom & $2.9 / \mathbf{1 . 3}$ & $2.2 / \mathbf{1 . 8}$ & $3.1 / \mathbf{2 . 5}$ & 2.6
\end{tabular}

SOURCE: 1995-2004 GDP data: for U.S., Dept. of Commerce, BEA; for all other countries, OECD. 2005 data for all G-7 countries: IMF World Economic Outlook, April 2005. Employment data: U.S., Dept. of Labor, BLS; Japan, OECD; Canada, Statistics Canada; France, Institut National de la Statistique et des Études Économiques; Germany, Bundesanstalt fur Arbeit; Italy, Istituto Nazionale di Statistica; U.K., Central Statistical Office. Non-U.S. GDP data, OECD.

${ }^{*}$ Calculated as GDP/civilian employment. 